
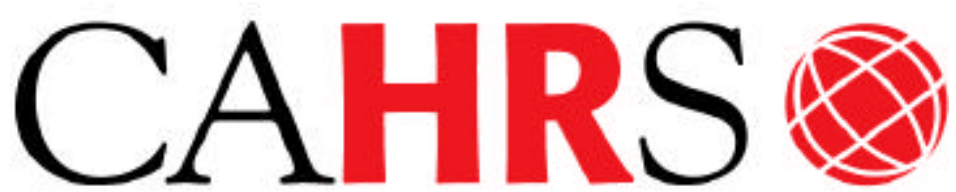

Center for Advanced Human Resource Studies
CAHRS / Cornell University 187 Ives Hall

Ithaca, NY 14853-3901 USA

Tel. 607 255-9358

www.ilr.cornell.edu/CAHRS/

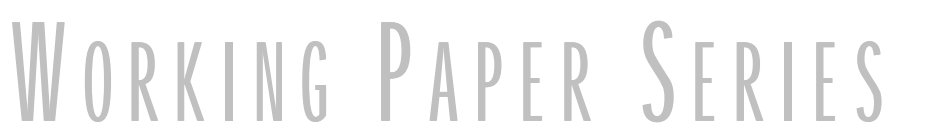

\title{
Diplomas for Learning, not Seat Time: The Impacts of New York Regents Examinations
}

John H. Bishop

Joan Y. Moriarty

Ferran Mane

Working Paper 97 - 31 


\title{
Diplomas for Learning, not Seat Time: The Impacts of New York Regents Examinations
}

\author{
John H. Bishop \\ Joan Y. Moriarty \\ Ferran Mane
}

Working Paper \# 97-31

\author{
Consortium for Policy Research in Education \\ and \\ Center for Advanced Human Resource Studies \\ New York State School of Industrial and Labor Relations \\ Cornell University \\ Ithaca, NY 14853 \\ jhb5@cornell.edu \\ jyml@comell.edu \\ fmane@riscd2.eco.ub.es
}

http://www.ilr.cornell.edu/cahrs/

This paper was prepared for presentation at School Finance for High Learning Standards, the fifth New York State Board of Regents Educational Finance Symposium, on Oct. 28, 1997, at the New York State Cultural Education Center, Albany, New York. The research reported on in this paper was supported by the Center for Advanced Human Resource Studies and The Consortium for Policy Research in Education (funded by the Office of Educational Research and Improvement, U.S. Department of Education).

The findings and opinions expressed in this report do not reflect the position or policies of the Office of Educational Research and Improvement or the U.S. Department of Education. This paper has not undergone formal review or approval of the faculty of the ILR School. It is intended to make results of Center research, conferences, and projects available to others interested in human resource management in preliminary form to encourage discussion and suggestions. 


\section{Diplomas for Learning, not Seat Time: The Impacts of New York State Regents Examinations}

\section{Introduction}

\section{The New York State Regents Examinations}

New York State has been administering curriculum-based Regents Examinations to high school students ever since June 1878. As Sherman Tinkelman, Assistant Commissioner for Examinations and Scholarships described in a 1966 report:

The Regents examinations are closely related to the curriculum in New York State. They are, as you can see, inseparably intertwined. One supports and reinforces the other.... These instruments presuppose and define standards.... They are a strong supervisory and instructional tool-- and deliberately so. They are effective in stimulating good teaching and good learning practices (Tinkelman, 1966 p. 12).

Sponsorship by the state Board of Regents is crucial to the role these examinations have played in setting and maintaining high standards and promoting reform. On occasions, examinations have been deliberately revised to induce changes in curriculum and teaching.

For years our foreign language specialists went up and down the State beating the drums for curriculum reform in modern language teaching, for change in emphasis from formal grammar to conversation skills and reading skills. There was not very great impact until we introduced, after notice and with numerous sample exercises, oral comprehension and reading comprehension into our Regents examinations. Promptly thereafter, most schools adopted the new curricular objectives (Tinkelman, 1966 p. 12).

The examinations are taken throughout one's high school career. A student taking a full schedule of college preparatory Regents courses would typically take Regents exams in mathematics and earth science at the end of $9^{\text {th }}$ grade; mathematics, biology and global studies exams at the end of $10^{\text {th }}$ grade; mathematics, chemistry, English and foreign language exams at the end of $11^{\text {th }}$ grade; a physics exam at the end of $12^{\text {th }}$ grade.

In 1993, about 56 percent of $9^{\text {th }}$ graders took the Mathematics Course I exam and, of these, 24 percent scored below the $65 \%$ passing grade. Similar proportions of $10^{\text {th }}$ and $11^{\text {th }}$ graders took the global studies, biology and English exams. Failure rates were 20 percent in global studies, 18 percent in biology and 13 percent in English. Those not taking Regents exams were typically in "local" courses that were considerably less challenging than Regents courses. A system of minimum competency tests in specific subjects set a minimum standard for those not taking Regents courses but, as in other states, the passing standard was low. 
The Regents exams are currently "low to medium" stakes tests, not "high" stakes tests. Exam grades count for less than a quarter of the final grade in the course and influence only the type of diploma received. Employers ignore exam results when making hiring decisions. During the 1980s, scholarships sponsored by the Regents were based on aptitude test scores, not Regents exam results. A passing score on Regents exams is not necessary for admission to community colleges or out of state colleges. Students were aware that they could avoid Regents courses and still go to college. Indeed some perceived an advantage to avoiding them:

My counselor wanted me to take Regents history and I did for a while. But it was pretty hard and the teacher moved fast. I switched to the other history and I'm getting better grades. So my average will be better for college. Unless you are going to a college in the state, it doesn't really matter whether you get a Regent's diploma. (Ward, 1994)

Indeed, the modest payoff to taking Regents exams may be one of the reasons why so many students have not been taking Regents courses. In 1995/96 only 40 percent of graduating seniors got a Regents Diploma signifying they took a series of Regents (or above) level academic courses and passed the associated exams.

Many parents support their children's preference for taking easier courses. They often pressured guidance counselors to let their child switch to easier courses where it would be easier to get good grades:

A lot of parents were in a 'feel good' mode. "If my kids are not happy, I'm not happy. "...Probably ... 25 percent ... were going for top colleges. They were pushing their kids hard. The rest --- 75 percent (I'm guessing at the numbers) said "No, that's too hard, they don't have to do that." ...If they [the students] felt it was too tough, they would back off. I had to hold people in classes, hold the parents back. [I would say] "Let the kid get Cs. It's OK. Then they'll get C+'s and then Bs". [But they would demand] "No! I want my kid out of that class!"

Teachers often supported students switching to easier classes.

.... frankly we couldn't get the staff to agree [to holding struggling or lazy students in Regents classes] either. They would say, 'He's not learning ... Get him out ... Let the kid drop into an easier class.' (guidance counselor's description of the situation prior to the high school switching to All-Regents, 1997)

The Statewide Shift to All-Regents

This is about to change. The Board of Regents has announced that students graduating in the year 2000 must take new six-hour Regents English examination and pass it at the 55\% level. The class of 2001 has the additional requirement of passing a six-hour examination in algebra and geometry. The class of 2002 must also pass two six-hour Regents examinations in 
global studies and American history. When laboratory science exams come on stream, the phase in of all five new required Regents exams will be completed with the graduating class of 2003. Once schools have adjusted to the new exams, the Regents intend to raise the scores necessary to pass from the $55 \%$ to $60 \%$ and then to $65 \%$. New York State is embarked on establishing the first high stakes curriculum-based external exit examination system in United States history.

The Regents believe that requiring all students to take and pass five Regents examinations will significantly improve student achievement. Skeptics point out that American students already take lots of standardized tests. They ask, "Why should a curriculum-based external exit examination system (CBEEES) like the Regents significantly improve incentives and learning?" The response of CBEEES advocates is that systems like the Regents Examination system have uniquely powerful incentive effects because they have the following six characteristics. They:

1. Produce signals of student accomplishment that have real consequences for the student.

2. Define achievement relative to an external standard, not relative to other students in the classroom or the school. Fair comparisons of achievement across schools and across students at different schools are now possible. Costrell's (1994) analysis of the optimal setting of educational standards concluded that more centralized standard setting (state or national achievement exams) results in higher standards, higher achievement and higher social welfare than decentralized standard setting (i.e. teacher grading or schools graduation requirements).

3. Are organized by discipline and keyed to the content of specific course sequences. This focuses responsibility for preparing students for particular exams on a small group of teachers.

4. Signals multiple levels of achievement in the subject. If only a pass-fail signal is generated by an exam, the standard will have to be set low enough to allow almost everyone to pass and this will not stimulate the great bulk of students to greater effort (Kang 1985; Costrell 1994).

5. Covers almost all secondary school students. Exams for a set of elite schools, advanced courses or college applicants will influence standards at the top of the vertical curriculum, but will probably have limited effects on the rest of the students. The school system as a whole must be made to accept responsibility for how students do on the exams. A single exam taken by all is not essential. Many nations allow students to 
choose which subjects to be examined in and offer high and intermediate level exams in the same subject.

\section{Assess a major portion of what students studying a subject are expected to know}

or be able to do. It is, however, not essential that the external exam assess every instructional objective. Teachers can be given responsibility for evaluating dimensions of performance that cannot be reliably assessed by external means.

What evidence is there that CBEEES tend to increase student achievement? Bishop (1996) has compared school policies, teacher behavior and student performance in the Canadian provinces with and without CBEEES. The analysis found that examination systems had pervasive effects on school administrators, teachers and parents. Students from EXAM provinces watched less TV and were more likely to have calculators and to use computers for schoolwork. Parents were more frequently reported to be interested in science, to care about learning math and more likely to talk to their child about what they were learning at school. In the provinces with external exams, schools were more likely to:

- employ specialist teachers of mathematics and science

- hire math and science teachers who had studied the subject in college

- have high quality science laboratories

- schedule extra hours of math and science instruction

- assign more homework in math, in science and in other subjects

- have students do or watch experiments in science class and

- schedule frequent tests in math and science class.

Public school students in the exam system provinces were 21 percent of a standard deviation better prepared in mathematics and 15 percent of a standard deviation better prepared in science than comparable students from provinces lacking such exams.

Bishop (1997) analyzed data from the 40 nations participating in the Third International Mathematics and Science Study and found that nations with CBEEES had substantively important-1.3 U. S. grade level equivalents in science and .9 U.S. grade level equivalents in mathematics-on the achievement of 13 year old students.

In the early 1990s, New York State was the only state with even a low/medium stakes curriculum-based external exit exam system (CBEEES). One way to assess the likely effect of requiring Regents exams is to examine the effects of the current voluntary low/medium stakes Regents examination system. If the current system has had positive effects on standards and achievement, it is reasonable to suppose that extending the system (without dumbing down the tests) to all students will improve achievement even more. If the current system has not caused 
an increase in dropout rates, there is reason to hope drop out rates will not escalate. It is clear that many students will not be able to pass these exams without working a good deal harder than they currently do. Will scheduling a longer school day result in an increase in the dropout rate? If the current voluntary Regents exams have pushed up dropout rates without improving achievement, the case for requiring them would appear to be significantly weakened?

The next part of the paper examines these issues by estimating cross-section models predicting test scores and dropout rate indicators and testing the "New York State is exceptional" hypothesis. Four outcomes will be examined: SAT-I test scores, $8^{\text {th }}$ grade NAEP mathematics achievement scores, the school enrollment rate at age 17 and the high school graduation rate.

The Regents also believe that setting higher standards will help graduates be more successful in both college and the labor market. Part 3 of the paper examines the second hypothesis that wages and earnings are higher for students who take more rigorous courses and/or graduate from high schools that require minimum competency exams.

Part 4 of the paper presents highlights from interviews with teachers and administrators of school districts that have already switched to an All-Regents curriculum. Lessons for the school districts about to undertake the switch are drawn.

\section{Is New York State Exceptional?}

New York's students are more disadvantaged, more heavily minority and more likely to be foreign born than students in most other states. Among northern states, only Maryland, Delaware and Illinois have a larger share of African-American pupils. Nationwide, only California has a higher share of its population foreign born and only California, Texas, Arizona, New Mexico and Colorado have larger Hispanic population shares. Literacy levels among adults are substantially below the national average (NEGP 1993, Vol. 2). Consequently, when one compares student achievement levels or drop out rates, family background must be taken into account.

Considering the high incidence of at-risk children, New York students do remarkably well. The proportion of students taking algebra, calculus, chemistry and physics is generally above national averages. A larger proportion of New York's $11^{\text {th }}$ and $12^{\text {th }}$ graders are taking and passing (9.4 percent) AP exams in English, science, math or history than any other state except Utah (NGEP 1993, Vol. 2). 


\subsection{Impacts on SAT-1 Scores}

Graham and Husted's (1993) analysis of SAT test scores in the 37 states with reasonably large test taking populations found that New York State students did better than comparable students in other states. They did not, however, test the statistical significance of the New York State effect and used an unusual log-log specification.

Table 1 presents the results of a linear regression predicting 1991 mean SAT-M + SAT-V test scores for the 37 states for which data are available. With the exception of the dummy variable for New York State, all right hand side variables are proportions-generally the share of the test taking population with the characteristic described. Clearly, New Yorkers do significantly better on the SAT than students of the same race and social background living in other states. When this model is estimated without the NYS dummy variable, New York has the largest positive residual in the sample. The next largest (Wisconsin's) positive residual is 87 percent of New York's residual. Illinois and Nevada have positive residuals that are about 58 percent of New York's value. Arizona, California, Colorado, Florida, New Mexico, Ohio, Rhode Island, Texas and Washington have negative residuals greater than 10 points. Many of these states have large populations of Hispanics and recent immigrants, a trait that was not controlled for in the analysis. This makes New York's achievement all the more remarkable when one considers that Hispanics and immigrants are a large share of its school children. 

Table 1

Determinants of Mean Total SAT-I Scores for States

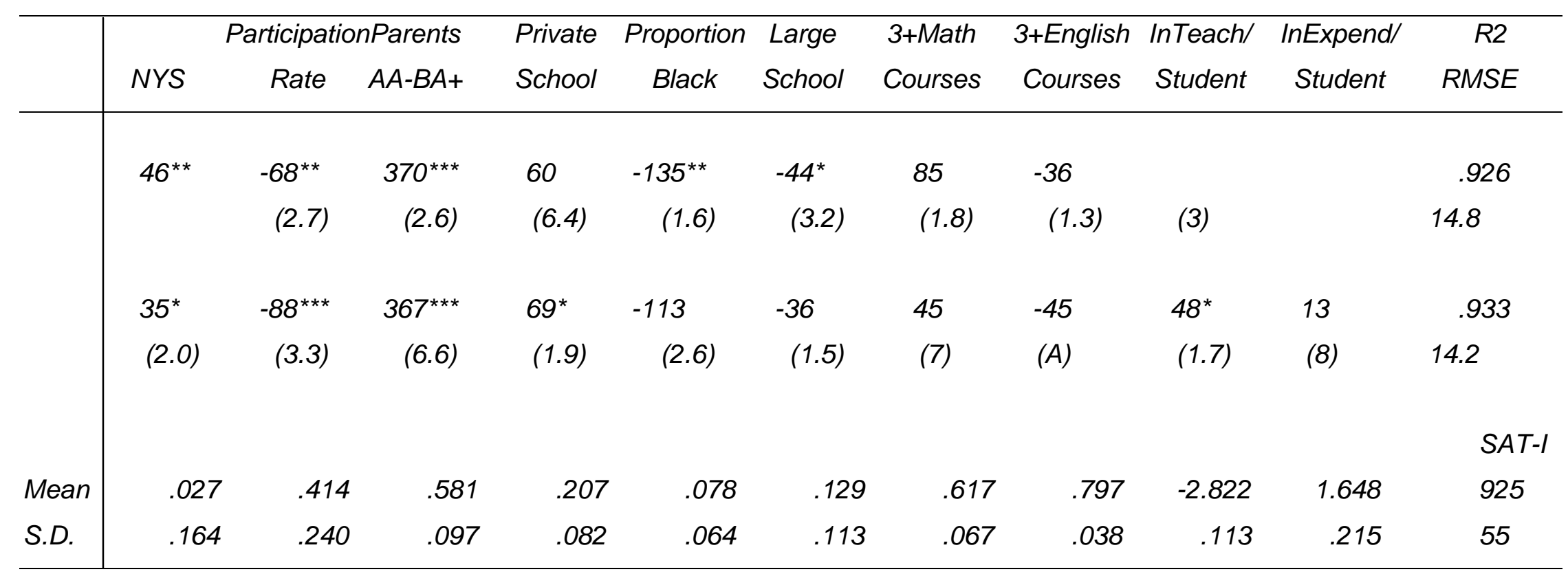


For individuals the summed SAT-V + SAT-M has a standard deviation of approximately 200 points. Consequently, the differential between New York State's SAT mean and the prediction for New York based on outcomes in the other 36 states is about 20 percent of a standard deviation or about three-quarters of a grade level equivalent.

Adding the teacher-pupil ratio and spending per pupil to the model reduces the NYS coefficient by 25 percent. It remains significantly greater than zero, however. The significant coefficient on teacher-pupil ratio suggests that heavy investment in K-12 schooling in New York State (possibly stimulated in part by the Regents exam system) may be one of the reasons why New York State students perform better than comparable students in other states.

\subsection{Impacts on Mathematics Achievement of $8^{\text {th }}$ Graders}

The New York is exceptional hypothesis can also be tested by analyzing data from the 1992 administration of the NAEP mathematics test to representative samples of $8^{\text {th }}$ grade students in 41 states and the District of Columbia. As with the analysis of SAT scores, state test score means were regressed on variables controlling for the socio-economic characteristics of the state's population and a dummy for New York State. The five variables that controlled for student background were: the proportion of people under age 18 who live in poverty, a schooling index for the adult population, percent foreign born, percent public school students who are black and percent public school students who are Hispanic. The results are presented in Table 2. Parents education, the poverty rate, percent black and percent foreign born all had significant effects on math achievement in the expected direction. New York State's mean NAEP math score was a statistically significant 9.6 points (or about one grade level equivalent) above the level predicted by the regression model. 
Table 2: The Impact of Regents Examinations on Achievement and High School Graduation

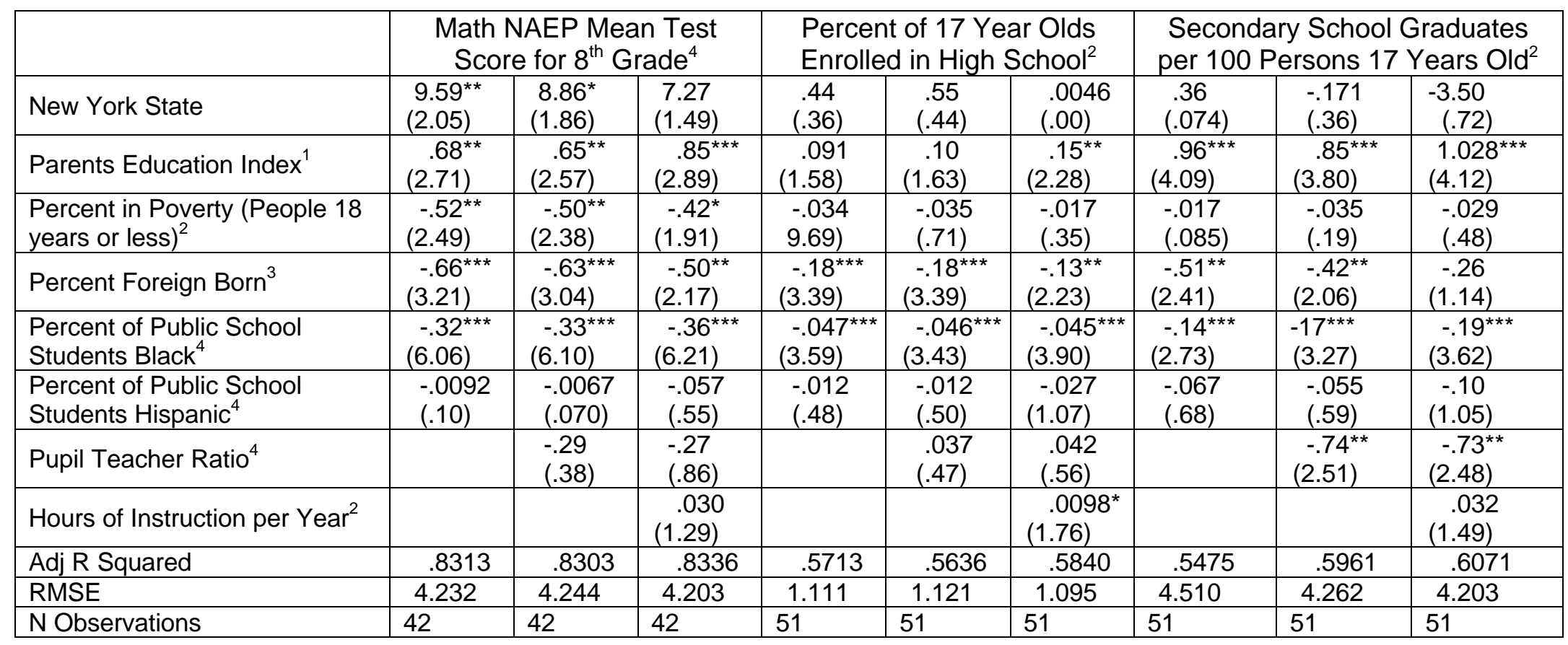

* Statistically significant at $10 \%$ level

** Statistically significant at $5 \%$ level

*** Statistically significant level at $1 \%$ level

${ }^{1}$ Average of the percent of parents obtaining a secondary school diploma and the percent of parents obtaining a university degree. Education in States and Nations. National Center for Education Statistics. U.S. Department of Education. 1991. Pg. 139.

${ }^{2}$ Education in States and Nations. National Center for Education Statistics. U.S. Department of Education. 1991. Pgs. 49, 73, 119, 129, and 149.

31990 Census of Population. Social and Economic Characteristics United States. Pgs. 174-79.

${ }^{4}$ Digest of Education Statistics. U.S. Department of Education. 1993. Pgs. 61, 76, and 120. 
One of the ways Regents exams might improve performance is by inducing the public to reduce the pupil-teacher ratios, keep schools open longer and assign more homework. Models were estimated that included these variables. While coefficients on these variables had the expected sign, only one-hours of instruction per year-came close to statistical significance. With only 42 observations, however, the power of these tests is low, so insignificant coefficients are to be expected. While statistically insignificant, the estimated impact of instruction hours is large enough to be substantively important. The point estimate implies that a 10 percent increase in scheduled hours will increase $8^{\text {th }}$ grade math scores by about a third of a grade level equivalent.

\subsection{Impacts on High School Dropout Rates}

Table 2 also presents the results of cross-state regressions predicting school enrollment rates at age 17 and high school graduation rates. The fear that the current New York State Regents exam system is pushing students out of school is groundless. New York State's high school dropout rate is not significantly different than that of other states with students from similarly disadvantaged backgrounds. Another piece of good news is that increasing the length of the school day or school year does not cause dropout rates to increase. Indeed they appear to fall. A 10 percent increase in the length of the school day or school year increases the enrollment rate at age 17 by 1 percentage point and the high school graduation rate by 3.5 percentage points. A 10 percent reduction in the pupil-teacher ratio increases the high school graduation rate by 1.5 percentage points. More homework also has a significant positive effect on graduation rates though not on enrollment rates at age 17. Models (not shown) that include $8^{\text {th }}$ grade mathematics test scores as a predictor find that they have a large positive effect on graduation rates.

\subsection{Does New York State Invest More in K-12 Education?}

The theory predicts that the existence of CBEEES will induce New York State to spend more on K-12 education and focus that spending on instruction. Indeed, New York's ratio of K-12 teacher salaries to college faculty salaries is significantly above average. New York teachers are also more likely to have masters degrees than are the teachers of any state except Connecticut and Indiana. New York ranks number 7 in both the teacher-pupil ratios and the ratio of per pupil spending to gross state product per capita (Bishop 1996).

Clearly, New York invests a great deal in its K-12 education system. If the cause of the high spending were a strong general commitment to education or legislative profligacy, we 
would expect spending to be high on both $\mathrm{K}-12$ and higher education. This is not the case. New York is number 1 in the ratio of $\mathrm{K}-12$ spending per pupil to higher education spending per college student.

\section{The Impact of Competency Exams and Rigorous Courses on Early Success in the Labor Market}

What is the impact of minimum competency test graduation requirement and taking more rigorous higher standards courses on college attendance rates and labor market outcomes? Many employers complain about the basic skills and work habits of recent high school graduates. A supervisor at New York Life Insurance, for example, asserted on television "When kids come out of high school, they think the world owes them a living" (PBS, March 27,1989$)$. Surely this generalization does not apply to every graduate, but the students who are disciplined and academically well prepared currently find it difficult to signal this fact to employers.

Why is it so difficult for high school graduates to signal their competencies to employers? One cause is the 1971 Supreme Court decision in Griggs vs. Duke Power which just about eliminated employer use of basic skills tests as a selection device for entry level jobs. Some employers ask for high school transcripts, but they are often late in arriving and the varying standards across courses make them hard to interpret. Other employers ask applicants to enter their high school GPA on the job applications, but often they do not check whether the information is accurate. Most employers do not even ask for information on grades.

Consequently, in most communities, competencies developed in the local high school are poorly signaled to employers. The lack of signals of achievement in high school tends to make employers with the best jobs reluctant to risk hiring recent high school graduates. They prefer, instead, to hire workers with many years of work experience because the applicant's work record serves as a signal of competence and reliability that helps them identify the most qualified.

\section{Minimum Competency Test Graduation Requirements}

Establishing a minimum competency exam, therefore, is one way a high school or a state education system can try to overcome this signaling problem and help its graduates get good jobs. The existence of the minimum competency test (MCT) graduation requirement is easily and cheaply signaled to all local employers. With the MCT requirement, the school's diploma now signals more than just seat time; it signals meeting or exceeding certain minimum 
standards in reading, writing and mathematics. This should make local employers more willing to hire the school's recent graduates.

This logic generates an interesting testable prediction: graduates of high schools with a MCT graduation requirement will earn more than graduates of schools without MCTs, even when socio-economic status (SES), test scores, grades, types of courses taken, working during senior year, current and past college attendance and other individual and school characteristics are held constant. This hypothesis will be tested in the two nationally representative longitudinal data sets-the National Educational Longitudinal Study (NELS88) and High School and Beyond (HSB) seniors-that contain information on MCTs mandated by state law or local school boards.

We will also test for impacts of MCTs on college attendance rates. However, as long as grades, test scores and course rigor are controlled, there is no reason to expect an effect. First, colleges with open-door admissions policies are common. Second, the MCT signal contributes little new information to college admission decisions, because colleges are already accustomed to evaluating transcripts and test scores when making admissions decisions.

The results of these analyses are presented in Table 3 . The students studied were the students in the two longitudinal studies who graduated from high school between January and September of their scheduled year of graduation. When earnings is the dependent variable, months attending college full-time and months attending college part-time (both current and past) are included as control variables. Otherwise the models predicting earnings and college attendance were the same. They are listed in the table's source note. As expected there was no consistent impact of MCTs on college attendance rates when SES, grades, test scores and types of courses were controlled. 
Table 3

\section{The Impact of Minimum Competency Test Graduation Requirement on College Attendance and Earnings of High School Graduates}

Females

Coef. T Stat

$.034^{\star} \quad 1.95$

$.060^{*} 1.82$

Earnings in 1993

1980 High School Graduates

Earnings in 1981

Earnings in 1982

Earnings in 1983

Earnings in 1984

Earnings in 1985

Prob. of College Attendance in 81/82

Prob. of College Attendance in 82/83

Prob. of College Attendance in 83/84

Prob. of College Attendance in 1985

$\begin{array}{llll}.019 & 0.71 & -.045 & 1.34 \\ .074^{* *} & 2.05 & -.013 & 0.40 \\ .032 & 0.98 & -.022 & 0.68 \\ .061 & 2.07 & .004 & 0.15 \\ .071^{\star \star *} & 2.68 & .026 & 1.12 \\ -.002 & 0.14 & .036^{\star * *} & 2.74 \\ .001 & 0.04 & .008 & 0.57 \\ .007 & 0.54 & -.009 & 0.62 \\ .001 & 0.08 & -.014 & 0.88\end{array}$

Source: Analysis of HSB and NELS88 data. Coefficients of the earnings models have been divided by mean earnings for that year. Controls include past and present college attendance, reading and math test scores in 12" grade, grade point average, courses taken in high school, extra-curricular activities, work for pay during senior year, TV and homework hours, religion, reading for pleasure, attitudes, indicator for being handicapped, family demographics, marital and parental status at the end of 12" grade, dummies for region and rural, suburban and urban residence. 
Impacts on earnings, by contrast, were substantial. MCTs had large (averaging 5.1 percent per year) effects on the earnings of women who graduated from high school in 1980. The effect was statistically significant in three of the five years (1982, 1984 and 1985) analyzed. MCTs had no effect on the earnings of the male members of the 1980 graduating class. Employer complaints that the high school diploma no longer guarantees a literate employee have increased since the early 1980s. This appears to have increased the signaling value of an MCT. For the 1992 graduating class, hourly wage rates were significantly (3.4 to 3.6 percent) higher where passing a MCT was a graduation requirement. In addition, the earnings of female graduates from MCT high schools were a significant 6 percent higher. Since the regression model includes controls for $12^{\text {th }}$ grade test scores, impacts that operate through harder study and more learning are not being counted in the above estimates. The total effect of MCTs on earnings will thus be even larger. If the signaling benefits of an MCT are even just a fraction of these levels, they substantially outweigh any potential losses from a small increase in dropout rates.

Theory predicts that the earnings effects of a MCT should depend positively on the rigor of the graduation standard. Requiring students to pass the much more difficult Regents exams should therefore strengthen the signaling effect described above. It may, however, increase dropout rates. ${ }^{5}$

\section{Taking More Rigorous Courses}

A second way schools can introduce higher graduation standards is to make it difficult or impossible for students to take courses like general math and remedial English that offer graduation credit for reviewing material supposed to have been learned in the first eight years of school. New York State's requirement that all students take and pass Regents examinations in five core subjects essentially forces all high schools to do just that. What is the likely effect of restricting access to basic and remedial courses? Studies have found that holding initial ability constant, that students who take remedial and/or basic courses get higher grades but learn less (Meyer 1992, Bishop 1996). In this paper we examine the effects of taking remedial courses on post-high school labor market outcomes and college attendance. High school graduates who have taken basic and remedial courses are compared to those who have not. Controls are included for as many confounding factors as possible: SES, ethnicity, $12^{\text {th }}$ grade test scores,

\footnotetext{
5 Analyses of NELS data by Dean Lillard (1997) and Lillard and DeCicca (1997a, 1997b) suggest that minimum competency test requirements for high school graduation may effect high school drop out rates. The size and sign of the effect is not clear,
} 
GPA, numbers of vocational and academic courses taken, extracurricular activities, hours doing homework, hours watching TV, attitudes and demographic characteristics. Almost identical models were estimated in three different nationally representative longitudinal data sets:

NELS88, HSB and the National Longitudinal Survey of 1972 (NLS72).

Results are reported in Table 4. The variable of interest takes on a value of 1 if basic or remedial classes have been taken in both English and mathematics. It takes on a value of .5 if basic or remedial classes have been taken in just one subject. Participation in such classes grew dramatically between 1972 and 1980 and then fell a little by 1992 . The mean value of this variable was .06 for the Class of 1972, .29 for the Class of 1980 and .215 for the Class of 1992 . It will come as no surprise that even when a full set of controls are included in the model, 1980 graduates who took both types of remedial courses were significantly less likely to attend college. 
Table 4

The Impact of Remedial Courses in English and Math on College Attendance and Earnings of High School Graduates

\begin{tabular}{|c|c|c|c|}
\hline & Females & \multicolumn{2}{|c|}{ Males } \\
\hline 1992 High School Graduates & Coef. T Stat & \multicolumn{2}{|c|}{ Coef. T Stat. } \\
\hline Hourly Wage Rate in 1993 & $\begin{array}{ll}-.009 & 0.71\end{array}$ & -.008 & 0.69 \\
\hline Earnings in 1993 & -.061 & $-.118^{* * *}$ & 3.05 \\
\hline \multicolumn{4}{|l|}{1980 High School Graduates } \\
\hline Earnings in 1981 & -.041 & -.026 & 0.64 \\
\hline Earnings in 1982 & -.032 & -.033 & 0.83 \\
\hline Earnings in 1983 & -.047 & -.040 & 1.03 \\
\hline Earnings in 1984 & $-.076^{\star *} 2.20$ & .042 & 1.40 \\
\hline Earnings in 1985 & $-.085^{\star * \star} 2.75$ & .016 & 0.59 \\
\hline Prob. of College Attendance in $81 / 82$ & $-.041^{\star \star *} 2.93$ & $-.063^{\star * *}$ & 4.01 \\
\hline Prob. of College Attendance in $82 / 83$ & $-.043^{\star * \star} 2.79$ & $-.038^{* *} 2$ & 2.17 \\
\hline Prob. of College Attendance in $83 / 84$ & $-.054^{* * *} 3.56$ & $-.038^{* * 2}$ & .23 \\
\hline Prob. of College Attendance in 1985 & $-.010 \quad 0.65$ & -.026 & 1.38 \\
\hline \multicolumn{4}{|l|}{1972 High School Graduates } \\
\hline Earnings in 1973 & -.069 & -.093 & 1.34 \\
\hline Earnings in 1974 & $-.163^{\star *}$ & -.077 & 1.41 \\
\hline Earnings in 1975 & -.082 & -.014 & 0.30 \\
\hline Earnings in 1976 & -.037 & $-.110^{* * *}$ & 2.76 \\
\hline Earnings in 1977 & .002 & -.056 & 1.50 \\
\hline Earnings in 1978 & .054 & $-.086^{\star \star}$ & 2.42 \\
\hline Earnings in 1979 & -.017 & -.050 & 1.45 \\
\hline Prob. of Attending College Fall 72 & -.016 & $-.035^{* * *}$ & 2.62 \\
\hline Prob. of Attending College Fall 73 & -.006 & $-.029 * \star$ & 2.28 \\
\hline Prob. of Attending College Fall 74 & .001 & .004 & 0.04 \\
\hline Prob. of Attending College Fall 75 & .012 & -.008 & 0.68 \\
\hline Prob. of Attending College Fall 76 & -.009 & -.012 & 1.12 \\
\hline
\end{tabular}

Source: Analysis of NLS72, HSB and NELS88 data. Coefficients of the earnings models have been divided by mean earnings for that year. Controls include past and present college attendance, reading and math test scores in $12^{\text {th }}$ grade point average, courses taken in high school, extra-curricular activities, work for pay during senior year, TV and homework hours, religion, reading for pleasure, attitudes, indicator for being handicapped, family demographics, marital and parental status at the end of $12^{\text {th }}$ grade and region. 
These students also generally earned less. A year after graduating, males from the class of 1992 who had taken both types of basic/remedial courses were earning a significant 12 percent less. For females in the class of 1992 the estimate of the loss is 6 percent, a number that despite its large size is not significantly different from zero. For 1980 and 1972 graduates, taking remedial courses is negatively related to earnings in twenty of twenty-four comparisons possible. Five of the coeffecients are significantly negative with a $p$ value lying below .025 for a one tail test. While these results suggest that fewer basic and remedial courses may be a good thing, one should not take them literally as estimates of the effect of eliminating the option of taking remedial courses. Since $12^{\text {th }}$ grade test scores, grades and attitude indexes are outcomes of earlier course selection decisions. This would tent to bias the coefficients on this variable toward zero. On the other hand, stable unmeasured characteristics such as low ability or laziness may be the reason students are taking basic and remedial courses. Selection effects of this type would bias the coefficient in the negative direction.

The findings presented in section 2 and 3 imply that curriculum-based external exit exams like New York State's Regents not only enhance student achievement, but also increase the earnings of graduating seniors even when measures of student achievement are held constant. So far, however, participation in Regents courses and exams has been voluntary. Requiring all students to take and pass Regents examinations in five core subjects to graduate from high school substantially raises the stakes. Regents examinations are considerably more challenging than the RCTs they will replace. Many students are going to find it very difficult to pass them. If they are to have a chance, schools will have to make the middle and high school curriculum more demanding and significantly increase the time and attention given to struggling students.

\section{All Regents High Schools: How did they do it?}

\section{What kinds of changes in school policies and resource allocation will be} necessary to move to an All-Regents curriculum in the five core subjects? This question was addressed by conducting interviews of teachers, administrators and school board members at ten high schools that have already moved (or are in the process of moving) to an All-Regents curriculum and have significantly increased the number of students taking and passing Regents exams. William Miles, Director of the Otsego-North Catskills BOCES managed the study and conducted many of the interviews. The interview schedule was designed jointly with William Miles and David Monk. The method of drawing the sample and conducting the interview and a 
more complete presentation of findings is available in Miles et al (1997). The site visitors wrote a short report about each district. In eight of the school districts, interviews were recorded. About 60 hours of audio tape were generated. The comments that follow are based on listening to the recorded interviews, a review of the reports and conversations with the interviewers.

\section{Generating support}

The districts that increased their participation in Regents exams to high levels did not accomplish the goal quickly and easily. The key to success was not getting a tax rate increase through the school board or introducing some new teaching system. In most cases what was required and accomplished was nothing less that a total transformation of the school's cultureboth for students and teachers.

The initiative generally came from a new district superintendent who was able to put a team of like minded individuals in key jobs such as high school principal and director of instruction. Staff and community support for the change was carefully cultivated. In many cases the goal of shifting to an All-Regents curriculum was not announced until many years after important initial steps had been taken and some early successes had been achieved. In most cases, the teachers and the community felt that the school was already doing a great job. They took pride in the accomplishments of the honors students. How could they be convinced to end the low expectations basic/local track into which struggling and lazy students were fleeing? The Regents exams and the report card outlining district level results provided the benchmark that the superintendent was able to use to shame and inspire teachers to raise the standards for all students. As one superintendent put it:

'External validation of what you're doing and forcing teachers, administrators and the community to look at yourself as reflected in the eyes of people outside of you and matching a standard that exists outside your school district was critical!"

The long history and prestige of Regents exams helped in selling the reform to parents.
"All-Regents was ... helpful for us. It was very concrete. It was something the parents could relate to. When parents thought of a Regents program in their own experience, they thought about students who were college bound. (School board president of an All-Regents school district)

Outside recognition was sought and excellence awards were frequently received.

"The whole community is walking around with their chests out. Which really helps out. There is a pride that this is what of an All-Regents school district). is today." (School board president 
[AIl Regents] put us up on a new standard. It made a change in the high school and [brought] the recognition of this high school as a place were positive things are happening. (President of the teachers union local in an All-Regents school district)

The outside recognition increased teacher and community support for the initiative. Praise for past accomplishments spurred teachers to raise standards even higher and work harder still. The focus on the external standard meant that the professional pride of the teachers became invested in getting marginal students "through the Regents exams." The visibility of each success made the extra work seem worthwhile.

Eliminating the local/basic track and the general increase in standards persuaded more students to take honors, AP and International Baccalaureate classes.

"Every level of kid in that classroom is getting a new challenge. Because we are an All-Regents high school, we are offering more AP classes. Kids are ready for that next challenge."

\section{Newport Junction Goes All Regents}

The goal, made public by the Superintendent in 1993, sounded simple: By the year $2000,75 \%$ of seniors at Newport Junction High School will graduate with a Regents diploma. Yet this statement generated protests from some parents and teachers who feared the higher standard would disrupt a school culture with which most seemed content. Why was such a move necessary and how would such an ambitious goal be achieved?

The movement towards more rigorous courses and requirements had been gaining momentum for several years at Newport Junction. In 1987, a new superintendent arrived with an agenda of improving achievement at the high school by putting an end to the pattern of mediocre performance by many students. One teacher, painting a more serious picture, described students "leaving school undereducated."

The initial challenge, however, was to persuade students, teachers, staff and the community that higher standards were needed. Most believed their school and students were already performing well. The superintendent and principal turned to external validators -- namely Regents and International Baccalaureate (IB) exams and diplomas -- to provided an benchmark of the school's performance in order to convince skeptics of the need for an increasingly demanding curriculum, "[External validators] were the best and only way in which we could get teachers and staff to see themselves as others might see them and not just keep looking in the mirror and seeing themselves as they would like to see themselves."

How did Newport Junction implement the change? First, local courses, the bottom track, were phased out, ultimately leaving students with only a choice between Regents-level and 
even tougher International Baccalaureate (113) classes. Barriers to entry into IB and Regents courses (i.e. qualifying exams and writing samples) were removed and no one was denied entrance into any accelerated courses. Nearly half of juniors and seniors are now taking at least one IB course. Second, students were strongly encouraged to take six or seven courses and the school day itself was expanded into a nine period day. Third, for students who fail the exam, one semester full course accelerated repeat classes are offered in order to provide students with a second chance of learning the material to pass the exams. Although the school has placed increased demand on the quality and quantity of student work, students are succeeding in part because the school's atmosphere has "kids believing in themselves that they can learn more."

The time demands on teachers and staff have increased dramatically since the initiative's launch with an estimated $25 \%$ to $40 \%$ of Newport Junction's students in need of extra help to meet the increased standards. For teachers more time is devoted to tutoring students to ensure their success in meeting the new challenges. A zero period has been added in which teachers are available before the start of the regular school day for extra help. Study halls have been eliminated and instead every period is covered by teachers in each subject who are available to answer questions and provide support. For staff, their tasks are reoriented towards the school's ultimate objective: increasing achievement. Staff members from coaches to administrative assistants have taken on the role of student mentors in addition to their regular duties. Furthermore, when once guidance counselors would have told a student struggling in an accelerated course to drop it, they are now routing them to zero period help sessions and teacher office hours.

Tutoring has been expanded. In addition to the extra time put in by teachers in one-on one tutoring, students have become an invaluable source of help for other students struggling to make the grade. IB students and Honor Society members complete their community service requirements by offering tutoring during open periods or before and after school. Also, community tutors and college students provide tutoring support after school and in the evening.

The impact these changes have had on the school's environment has been remarkable. More students than ever are taking and passing Regents and IB courses. In 1996, sixty-six percent of students received Regents diplomas, up nearly ten percent from seven years earlier, and over forty percent received International Baccalaureate degrees. Over $80 \%$ of Newport Junction's enrollment took Regents exams in English, US History/Government, Global Studies and Sequence Math I and II. The percent of students who took and passed Regents exams exceeded eighty percent in all subjects but Biology and Sequence II Math. Furthermore, the 
percent of average enrollment who passed Regents exams in Global Studies and Sequence I and II Math exceeded ninety percent and over two-thirds of enrolled students also passed Regents exams in English, US History/Government and Biology. Also, by introducing such as IB Art, IB History of Theatre and IB Music, the school was able to attract into accelerated courses students who did not think of themselves as academically gifted. When these students achieved success, many decided to enroll in IB Science, English and History. In addition, even though sports eligibility requirements were tightened, eligibility and participation rates have not fallen.

The message to students has been altered to not only stress that more is expected of them but that help will be there if they need it. This atmosphere allows students to be more comfortable taking risks, "If kids buy into the school the easier it is to get them to take tougher courses." Success is possible if students believe they can achieve and if they know resources are available to help them meet the expectations. Newport Junction is a case in point.

\section{A Focus on Struggling Students}

All of the districts substantially increased the time and resources devoted to teaching and tutoring struggling students. Since they had initiated the raising of the bar, school administrators felt a moral obligation to do everything in their power to help students succeed.

"You need to ... provide the remedial and tutorial support that every individual kid needs. It's a terrible thing to put in a tough program that kids are going to fail. Every one of these kids can do it - they take a different amount of time to do it." (School board president in an All-Regents School District) The guidance counselor met with incoming freshmen and developed a plan whose goal was obtaining a Regents diploma. The milestones were tracked and if a student started having difficulties the counselor arranged tutoring. The extra time was obtained in a variety of ways:

- More homework was assigned-especially for students formerly in local courses.

- Struggling students were assigned to Stretch Regents courses that take 1.5 or 2 years to cover material conventionally covered in one year in a standard Regents course.

- Struggling students were assigned to classes with more than five periods a week. A number of the schools that settled on this option had tried two-year Stretch Regents courses and felt that extra time in a one-year period worked better.

- Increased summer school attendance especially for struggling primary and middle school students. 
- Study halls were reduced because most students "do not use study halls productively" and regular tutoring sessions were substituted.

- Extra periods at the beginning or end of the school day were added and used for giving struggling students extra help.

- Students in the National Honors Society and the International Baccalaureate program provided peer tutoring.

\section{Teachers were Inspired to Work Harder}

"[Teachers] worked above and beyond the contract nobody asks them to do it...I've never worked in a place like this before! " (Principal of an All-Regents high school)

"The [teachers] were willing to give their every effort and time above and beyond the school day. They would stay for hours on end late in the...evening...She [the principal] presented it so well. She's just a motivator!" (School secretary at the same All-Regents high school)

In many schools the increase in teacher time devoted to tutoring was also accomplished by relieving them of hall duties, lunchroom supervision and study hall supervision. In one school the role of department chair was eliminated and the released time formerly given to department chairs was reallocated to teaching and tutoring. In some schools teaching assignments were no longer allocated by seniority. The best teachers were reassigned to classes with lots of struggling students. In some schools fully qualified teachers were hired as teaching assistants to provide tutoring. Nighttime review sessions were offered in the months preceding the Regents exams. Teacher contracts were not renegotiated, but local union leaders sometimes chose not to make an issue of things that in the past might have led to a grievance.

In one district many teachers could not adapt to the new way of doing things and left. Young teachers who believed the All-Regents goal was both desirable and feasible were hired as replacements.

\section{Implications for State Policy}

Requiring that all students reach the Regents standard in five core subjects will significantly increase student achievement, college attendance and completion and the quality of jobs that students get after high school. The biggest beneficiaries of the policy will be the students, often from disadvantaged backgrounds, who have been allowed to avoid rigorous courses in the past. In the All-Regents high schools there was a massive reallocation of teacher 
time and resources towards struggling students. It was these students whose achievement rose the most. Their probability of going to and completing college rose significantly.

It is not clear, however, that the parents of struggling students will see it that way. When the principal of an All-Regents high school was asked about whom opposed the elimination of the easier local courses, she said:

"Parents of children ... who ... felt [their kids] couldn't do it .... [One parent approached her in the school parking lot] "She started yelling at me. She told me she hated the All-Regents high school. Her kids were not as successful. If you sit in a consumer math class you get a 90. If you sit in a sequential math class, you have to struggle to get a 65....She was very angry about it....Parents are a big obstacle.... Your kids don't want to do this. They're going to complain about it. Which means you are going to work harder as a parent."

Once students start failing Regents exams and having to repeat courses in order to graduate, there will be a crescendo of complaints. Claims will be made that schools have not done enough to help students succeed on the new exams. What can the Regents and the state legislature do to help local schools meet their obligation to help students meet the new higher standards? How can the number of dropouts and graduation delays be minimized?

- Staff development should start at least two years in advance of the first administration of new exams. The middle school curriculum needs to become more demanding so staff development programs need to be developed for middle school teachers.

- Instruction in how to write the analytic and expository essays expected on the Regents exams needs to start no later than ninth grade. Schools should be encouraged to require students take a demanding one semester analytic writing course probably during ninth grade (small class size will be essential).

- Offer students who fail a Regents exam in June the opportunity to take intensive review courses (with at least 100 hours of instruction) over the summer and retake the Regents exams in September. School districts would be required to offer such courses (small districts could contract with a BOCES or community college). Districts would also be required to offer summer school opportunities to middle and high students who are behind grade level and at risk of failing Regents exams.

- If districts do not currently have the authority to require students to attend summer school or to require attendance after school or on Saturdays, they should be given the authority.

- Middle and high school students should attend school for 8 not 6 hours a day. Students who are significantly behind would be scheduled into classes with more than 5 periods a week. Students who do not need extra help could use the additional time for sports, clubs, elective 
courses, accelerated courses, or paid employment. The costs of increasing the length of the school day should not be subject to spending caps in state funding formulas.

- Teachers should be paid extra for working longer hours. Inspiring leadership that induces teachers to work way beyond the contract for no additional pay will not be available in most districts. Costs of tutoring, longer school days, review sessions and staff development that are associated with preparing students for Regents exams should not be subject to caps in state funding formulas. A special funding formula should be developed for districts that have large numbers of disadvantaged pupils and low first grade test scores.

- Two-year stretch Regents courses should give the student two Carnegie units of credit. Courses scheduled for seven or more periods a week should also generate more than the standard one Carnegie unit.

- Teachers should grade the Regents exams in centralized regional locations under the guidance of well-trained leaders. Canadian teachers who have served on grading committees for their provincial exams describe it as "a wonderful professional development activity (Bob 1996)." Having to agree on what constituted excellent, good, poor, and failing responses to essay questions or open-ended science and math problems resulted in a sharing of perspectives and teaching tips that most found very helpful. Scoring rubrics would be developed centrally so as to maintain consistent standards across the state.

- During a four-year period of adjustment to the new exams, teacher grades and Regents exam results should both be given weight in deciding whether a student passes a course.

- After a four-year period of adjustment to the new exams, Regents exam grades should be a part of the student's overall grade in the course. 


\section{References}

Bishop, John. (1996) "The Impact of Curriculum-Based External Examinations on School Priorities and Student Learning." International Journal of Education Research.

Bishop, John. (1997) "The Effect of National Standards and Curriculum-Based External Exams on Student Achievement." American Economic Review, May 1997.

Bob, Interview conducted in Calgary Alberta in May 1996.

Costrell, Robert. (1994) "A Simple Model of Educational Standards." The American Economic Review.Vol. 84, \# 4, Sept., 956-971.

Graham, Amy and Husted, Thomas. (1993) "Understanding State Variation in SAT Scores." Economics of Education Review, Vol. 12, No. 3, 197-202.

Kang, Suk. "A Formal Model of School Reward Systems." in Incentives, Learning and Employability, edited by John Bishop, Columbus Ohio: National Center for Research in Vocational Education, 1985.

Lillard, Dean. (1997) "The Effects of State Mandates and Markets on Time to Completion and High School Dropout Decisions." College of Human Ecology, Cornell University, 1-32.

Lillard, Dean and DeCicca, Phillip. (1997a) "The Effects of State Graduation Requirements on High School Dropout Decisions." College of Human Ecology, Cornell University, 1-27.

Lillard, Dean and DeCicca, Phillip. (1997b) "State Education Policy and Dropout Behavior: An Empirical Investigation." College of Human Ecology, Cornell University, 1-23.

Miles, William, John Bishop, Jim Collins, Judy Fink, Marla Gardner, John Grant, Samid Hussain, David Monk, Edward Moore, Joan Moriarty, and Marie Warchol (1997). Ten Case Studies of 'All Regents' High Schools: Final Report to the State Education Department, Albany, New York.

National Center for Educational Statistics. The Digest of Education Statistics: 1991. Wash. D.C.: US Department of Education, 1991.

National Center for Educational Statistics. The Digest of Education Statistics: 1993. Wash. D.C.: US Department of Education, 1993.

National Center for Education Statistics. Education in States and Nations. Wash., D.C.: U.S. Department of Education. 1991.

National Education Goals Panel. Data for the National Education Goals Report: 1995. Vol. 1, Washington, DC: U.S. Government Printing Office, 1995, 1-199.

Tinkelman, Sherman N. (1966) "Regents Examinations in New York State after 100 Years." Albany, N.Y: The University of the State of New York, The State Education Department, 115.

U.S. Census Bureau. 1990 Census of Population. Social and Economic Characteristics U.S.

U.S. General Accounting Office, Educational Testing: The Canadian Experience with Standards, Examinations and Assessments. (written by Kathleen D. White) GAO/PEMD-93 -11, Washington, D.C., April 1993, 1-74.

Ward. "A Day in the Life." N.Y. Teacher. Jan. 1994, Albany, N.Y. 